\title{
The design of inclined tied arch railway bridges over the M56
}

\author{
K. I. MAJID, J. E. SPINDEL \& M. S. WILLIAMS
}

\section{Professor Chin Fung Kee, University of Malaya, Malaysia}

The Authors and those responsible for the project are to be commended for adopting the tied arch for the two railway bridges. The tied arch is a structure characterized by its slenderness and elegance and the high efficiency in the utilization of the materials of its major components. Outstanding examples are the Villa Franca bridge across the Tagus and the prestressed concrete hangars at Helsinki Airport. The main reasons for the tied arch being an economic structure are that the hangars are pure tensile members-this allows the entire cross section to be fully stressed-and that the hangar system offers scope for the reduction of the bending moments in the main beams to values much lower than would prevail in other forms of beam structures of corresponding span.

52. The Authors have given stability as one of the reasons for inclining the two arches towards each other. In the simple approach of considering the tied arch to carry the direct loads and the beam system to meet the bending moments, it has been shown ${ }^{7-\theta}$ that there is little increase in stability to be gained by fixing the crown of the arch in position. From the point of view of elastic stability there may be little advantage in raking the two arches to meet overhead at mid-span. With the extensive overhead bracing which the Authors have incorporated in their design in the form of a web extending over nearly a third of the span, it would seem that arch stability would no longer present a problem. This condition would also prevail if the same extent of overhead bracing were to be provided for vertical plane arches. It would be interesting to know what other reasons the designers had for adopting the inclined arches. It would appear that vertical arches would enhance the appearance and provide more headroom for a given width of bridge.

\section{Mr P. Tveit, Danish Engineering Academy. Aalborg. Denmark}

With reference to the excellent Paper I noted with special interest that the Authors began with an arch bridge with inclined hangers, but found that vertical hangers were preferable. The conclusion might have been different had inclined hangers with multiple intersections been tried.

54. Figures 17 and 18 give dimensions and details of a network arch ${ }^{10}$ designed to carry $10 \mathrm{t} / \mathrm{m}$ of rail. Stresses are acceptable to most building codes.

55. Dimensions of arch are decided by uniform loading on the full length of the bridge. This gives a maximum compression of $145 \mathrm{~N} / \mathrm{mm}^{2}$ between points 7 and 47 in the arch.

56. The wire ropes for the hangers are calculated as in reference 11 . The smallest uniform load that can make a hangar $(10-15)$ relax is $16.5 \mathrm{t} / \mathrm{m}$ of rail. This is 2.6 times the dead load at the lower chord. Only half of the traffic load is assumed to occur often enough to cause fatigue. Still the risk of fatigue failure determines the dimensions of the hangers.

57. The influence lines for the lower chord show that the longitudinal bending in the concrete slab is smaller than the transversal banding. The slab is fully prestressed in the transverse direction and partly prestressed in the longitudinal direction. Maximum stress in concrete is $10 \mathrm{~N} / \mathrm{mm}^{2}$. Side spans could have been attached at

Paper published: Proc. Instn Civ. Engrs, 1971, 50, (October) 139-150. 
Influence lines for $\frac{1}{2}$ of double track rajiway bridge

Cross sections for half bridge

\begin{tabular}{|c|c|c|}
\hline Lane: & $F=250 \mathrm{dm}^{2}$ & $l=520 \mathrm{dm}^{4}$ \\
\hline & $\begin{array}{l}F=6.24 \mathrm{dm}^{2} \\
E=2100 \mathrm{t} / \mathrm{cm}^{2}\end{array}$ & $l=30 \mathrm{dm}^{4}$ \\
\hline & $F=18 \mathrm{~cm}^{2}$ & $E=1500 \mathrm{t} / \mathrm{cm}^{2}$ \\
\hline
\end{tabular}

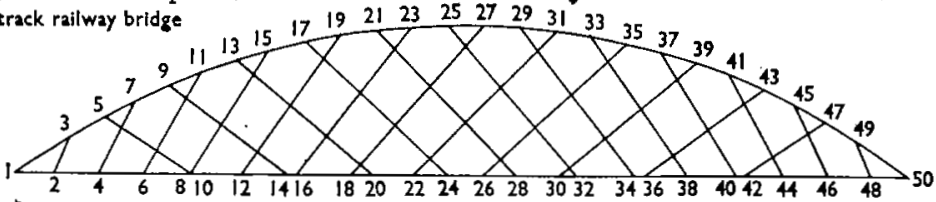
$2946^{31.22} 3251^{3410} 3605^{3845}$
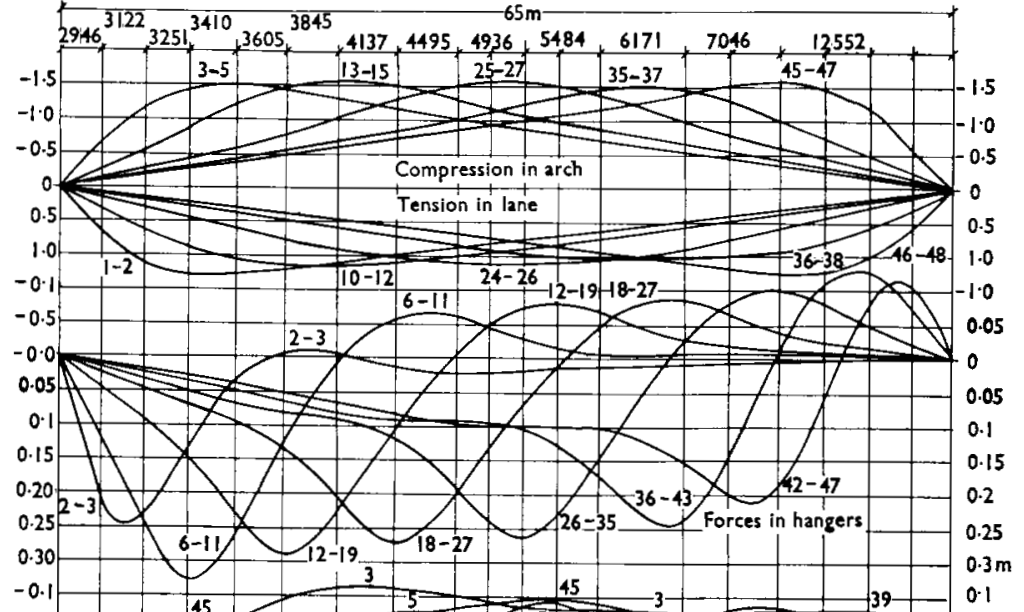
$10^{-4} \mathrm{rad} / \mathrm{t}$
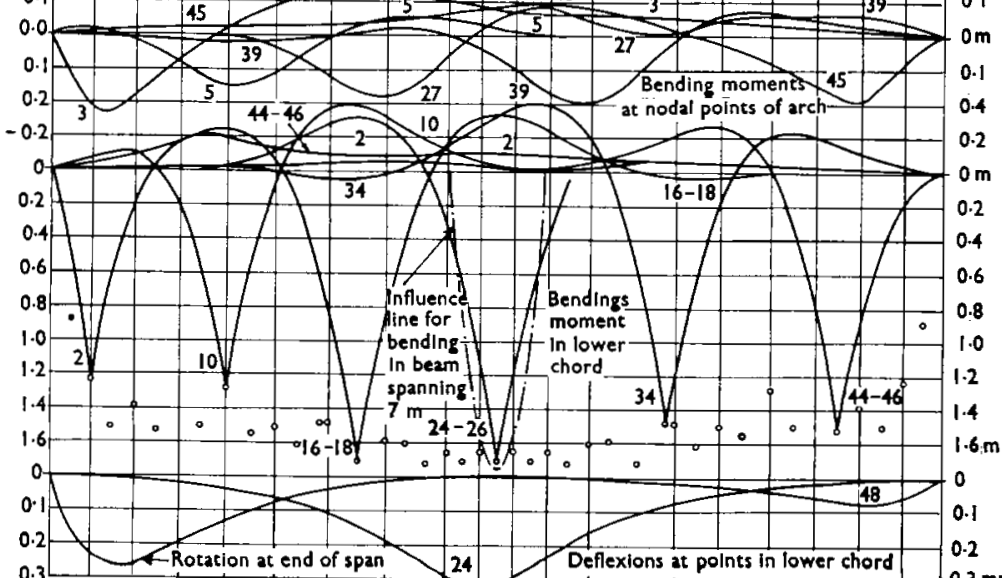

0.3

Fig. 17. Influence lines calculated by STRUDL. The difference in slope between two adjoining hangers is $3^{\circ}$. The slope of the steepest hanger is $67^{\circ}$. The arch is a sector of a circle 


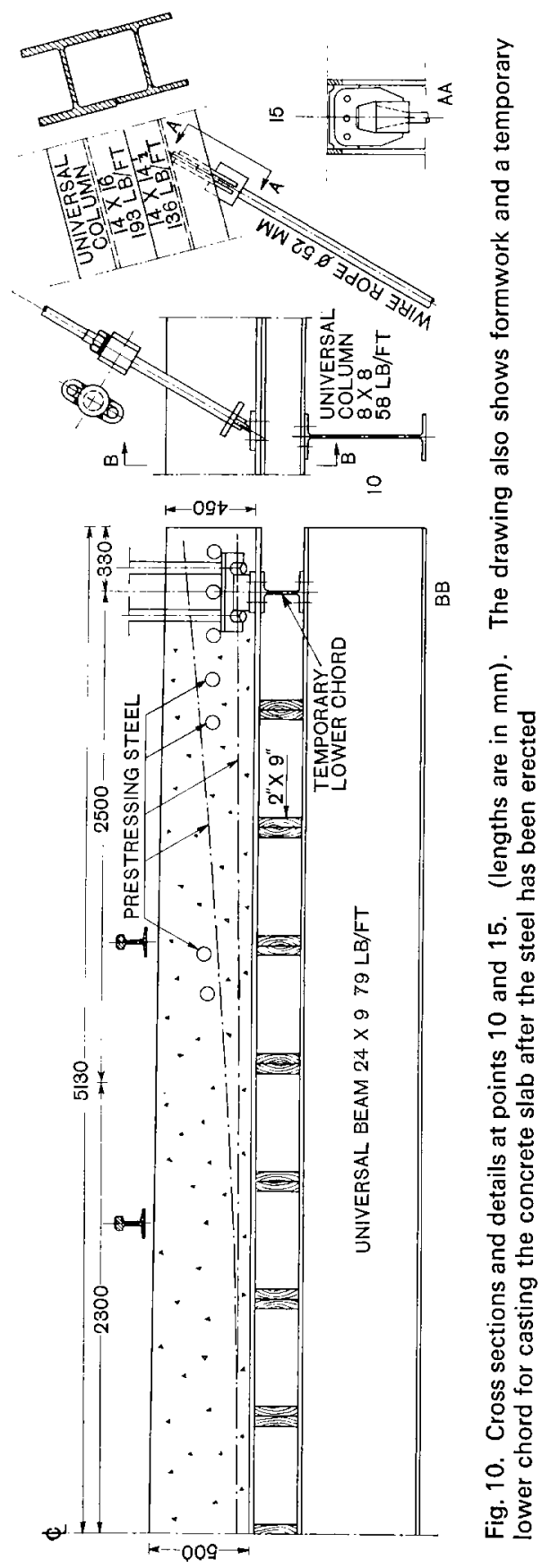


the ends of the $\operatorname{arch}^{12}$ but have been omitted so that the influence lines could be on one page.

Steel weights, excluding bearings and racks are:

structural steel, mainly St 52-3 (approx. BS 968)

longitudinal reinforcement $\sigma_{0.2}=1450 \mathrm{~N} / \mathrm{mm}^{2}$

transversal reinforcement $\sigma_{0.2}=800 \mathrm{~N} / \mathrm{mm}^{2}$

ribbed reinforcement $\quad \sigma_{0.2}=400 \mathrm{~N} / \mathrm{mm}^{2}$

58. This compares favourably with steel weights $274 \mathrm{t}$ and $497 \mathrm{t}$ for double track railway bridges spanning $58 \mathrm{~m}$ and $76 \mathrm{~m}^{13}$

Professor K. A. Everard, Makerere University, Kampala

The Authors are to be congratulated on their elegant treatment of what can be, aesthetically, a most unsatisfactory structural form. Tied arches, bowstring girders and vierendeel girders with curved top chords, all closely related structures, can be unpleasing particularly where the arch springing joins the tie and the vertical abutment. That notwithstanding, and bearing in mind the need for rolling the completed bridge superstructure in place during very limited access times, the designers have produced a sound and attractive solution. It would be of interest to know the cost of the bridges.

60. In 1954 I was responsible for the design and construction of a tied arch, which perhaps overcame the aesthetic objections referred to. The bridge was constructed in situ and could not have been rolled into place. It is not suggested, therefore, as an alternative to these present bridges, but rather to bring to notice another structural system.

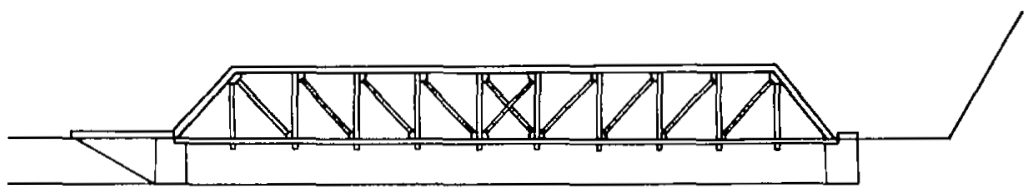

200 ft span pratt truss bridge on mass concrete abutments
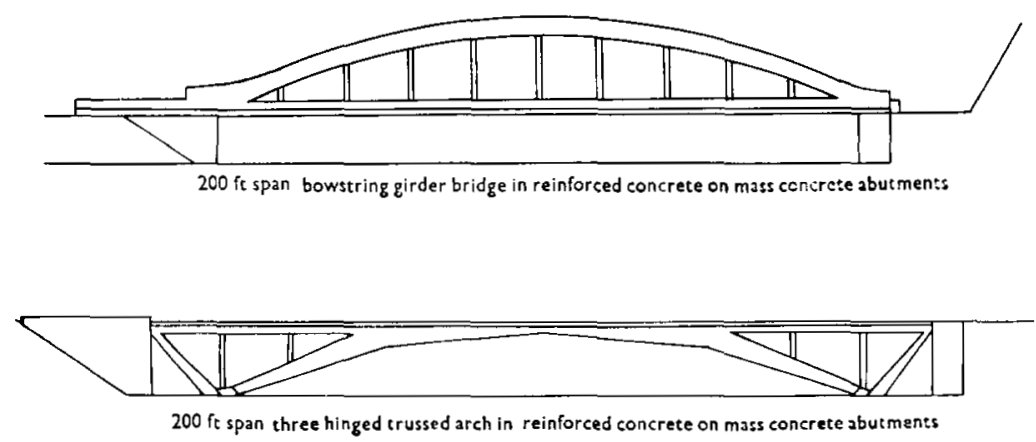

Fig. 19. Alternative designs for the Negro River bridge 

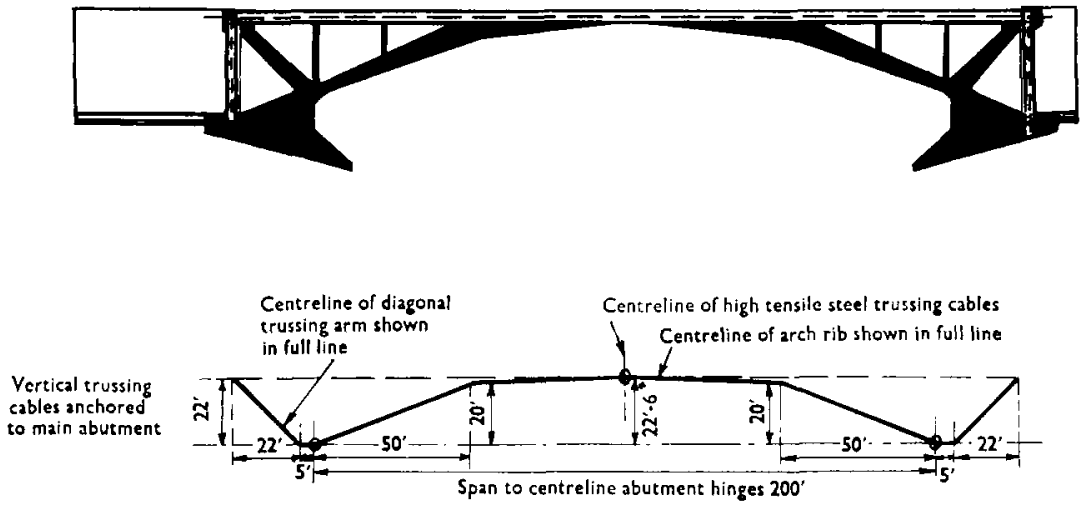

Fig. 20. Articulation diagram

61. This bridge was constructed to replace an old wrought iron truss over the Negro River in Jamaica, which had been destroyed during the hurricane of 1951 . Designed in 1954 the bridge was completed in 1956 at a cost of $£ 70000$. The system was a reinforced concrete three-pinned arch of span $200 \mathrm{ft}$ with an active tie at deck level consisting of stressed freyssinet cables.

62. Three alternatives were considered, elevations of which are shown in Fig. 19. Thankfully, steel shortages prevented the adoption of the first since the delivery time for the steel superstructure was three years. A concrete bridge was easily justified on the grounds of the saving of foreign exchange, cement aggregates and timber all being available from Jamaican sources.

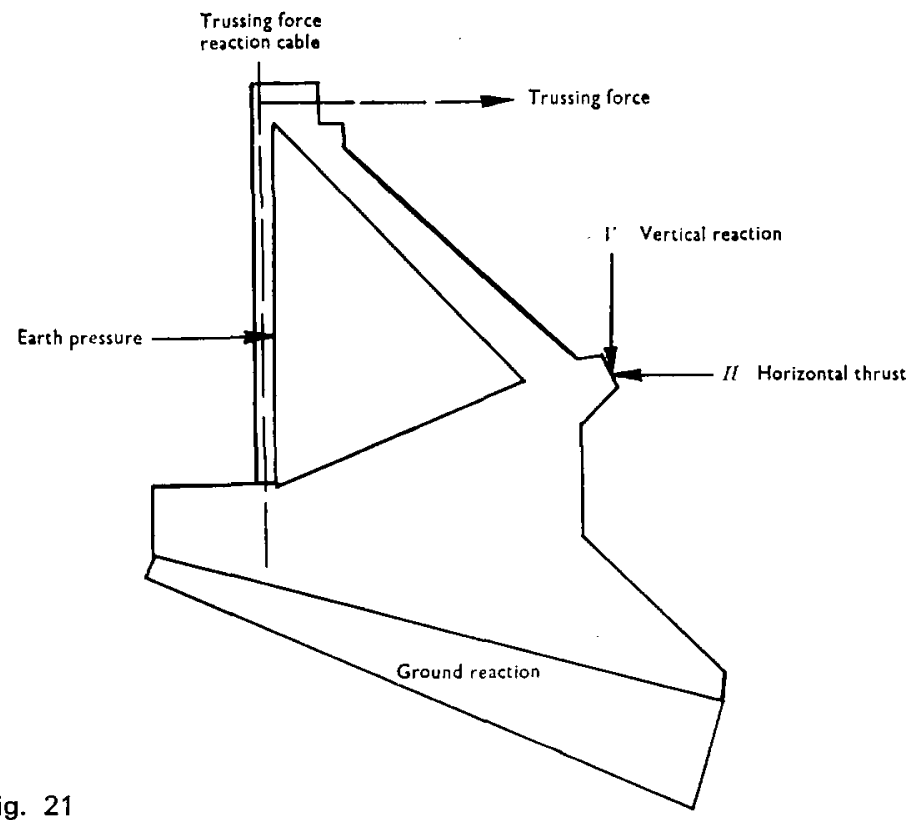


63. The structural action of the bridge is clearly seen from the articulation diagram in Fig. 20. The arch between springings was a normal three-pinned arch of span rise ratio 9:1. A long approach embankment required as small a rise as possible. Normally, the foundations for an arch of this low rise would have been uneconomic unless on rock. The cable truss resulted in abutments of reasonable mass although they were founded on gravel. The trussing system ran through the bridge deck but was virtually independent of it although at the completion of construction the cable tubes were grouted as a protection against corrosion.

64. With this system it is obviously not possible to prestress against the full value of the horizontal thrust and the truss action modifies the abutment design. The free body diagram (Fig. 21) shows the forces on the foundations.

65. Another feature which may be mentioned was the use of concrete hinges instead of the more normal cast iron and steel pins normally in use.

\section{Messrs Majid, Spindel and Williams}

We should like to thank Professor Everard, Professor Chin Fung Kee and Mr Treit for giving details of their experience in the design of similar arch bridges.

67. It is difficult to decide between the aesthetic appearance of an inclined arch bridge and one with vertical arches since this is largely a subjective matter. We feel that in this situation the inclined arches improved the appearance of the structure. However, this was only one factor in deciding the shape of the bridge. The bridge carries two rail tracks and therefore the width and headroom requirements were fixed. Further, the deck slab had to be sufficiently wide to be supported on columns outside the tracks, in order to construct foundations without interfering with rail traffic. By making the arches of the bridge inclined, while allowing sufficient headroom, it was possible to reduce the space enclosed and thus reduce the material required for tying the arches together at the crown. The increase of stability of the bridge from inclining the arches was needed particularly during the rolling-in operation, as the transverse and twisting forces were unique for a structure of this size.

68. The inclined arches made the bridge a stronger space structure whose torsional stiffness, including that contributed by the slab, the beams and the arches, could be utilized to withstand the rolling-in stresses. Further, the interaction of the various components of the bridge could be assessed accurately by the three-dimensional analysis of the complete structure. Inclined arches also improve the stiffness of the structure against wind forces. For these reasons it is difficult to compare this bridge with one consisting of two parallel arches as those in references 1-3.

69. Mr Treit suggests that inclined hangars with multiple intersections could have been used with advantage. This possibility was considered and recognized. However, the practical difficulty of providing interconnexion outweighed the advantages in a structure of this size. In addition hangars may have to be replaced or adjusted during inspection throughout the life of the bridge and vertical hangars present fewer practical problems in this respect.

70. On structures of this kind it is difficult to quote costs without giving misleading information. It is not possible to isolate structural costs from charges for rollingin, temporary girders, winches and so on, together with the railway costs for track re-laying and the interruption and replacement of overhead electrical equipment. An initial assessment of total costs showed that the cost of these structures with their small construction depth compared favourably with more traditional solutions for this site where the motorway had to be located in an expensive cutting to pass under the railway lines.

71. In the case loading diagrams in Figs 8 and 10 of the Paper a negative sign should be placed in each of the unmarked bridge quarters. This denotes an equal and opposite loading to the quarters of the bridge in which a plus sign indicates downward loading. 


\section{References}

7. Godden W. G. The lateral buckling of tied arches. Proc. Instn Civ. Engrs, 1954, 3, Part 3, August, 496-514.

8. Chin Fung Kee. The design of the unbraced stabbogen arch. Struct. Engr, 1959, 37, 265-270.

9. Chin Fung Kee. The evaluation of the design load for the stabbogen arch. Jnl Instn Engrs, Malaya, 1960, 1, No. 1, 22-27.

10. TVEIT P. Network arches for railway bridges. Report 7205, Ren og Anvendt Mekanik, DIAB, Aalborg, Denmark, 1972.

11. TVEIT P. Design of network arches. Struct. Engr, 1966, July, 249-259.

12. STEIN P. and WILD H. Das Bogentragwerk der Fehmarnsundbrucke. Stahlbau, 1965, June, 171-186.

13. Gut H. and Schuwerk O. Die Brücken der SBB im Raume ZiegelbrückeWeesen. Schweizerische Bauzeitung, 1971, 14, 1017-1030. 